\title{
Os obstáculos para a produção de grãos na Amazônia: o caso do estado do Amapá
}

\author{
The obstacles to grain production in Amazonia - the case of the State \\ of Amapá \\ Claudia Chelala ${ }^{1}$ (D), Charles Chelala ${ }^{1}$ (D) \\ 'Departamento de Meio Ambiente e Desenvolvimento, Universidade Federal do Amapá (UNIFAP), Macapá (AP), Brasil. E-mails: \\ cfchelala@gmail.com; charleschelala@gmail.com
}

Como citar: Chelala, C., \& Chelala, C. (2022). Os obstáculos para a produção de grãos na Amazônia - o caso do Estado do Amapá. Revista de Economia e Sociologia Rural, 60(2), e249653. https://doi.org/10.1590/1806-9479.2021.249653

\begin{abstract}
Resumo: O Amapá é a unidade da federação que possui a menor participação percentual do setor primário na composição do seu PIB estadual. No período do então Território Federal do Amapá (1943-1988), o setor primário caracterizou-se pelo extrativismo e pela silvicultura. O estado possui uma área de cerrado de aproximadamente um milhão de hectares, dos quais, estima-se que 400 mil hectares podem ser considerados potencialmente propícios à agricultura. A partir de 2013, registrou-se o ingresso de produtores rurais, devido ao movimento de expansão da produção de soja na Amazônia. Decorridos oito anos do início desse processo, o ano de 2021 aparenta representar o de maior desafio para a continuação das atividades, em razão do aprofundamento do imbróglio fundiário e ambiental que envolve o setor, com desdobramentos administrativos, jurídicos e policiais. A grande maioria dos produtores rurais não possui licença ambiental que os autorize realizar os preparativos para o início do cultivo. Assim, a produção deste ano encontra-se seriamente comprometida. Observa-se um contexto de insegurança jurídica, que consolida o ambiente de incertezas prejudicial ao desenvolvimento da produção. Este artigo tem o objetivo de analisar as causas da situação de engessamento do setor, bem como prospectar possíveis cenários advindos deste contexto.
\end{abstract}

Palavras-chave: desenvolvimento rural, instituições, política fundiária, política ambiental.

Abstract: Amapá is the state with the lowest percentage share of the primary sector in the composition of its state GDP. In the period of the then Federal Territory of Amapá (1943-1988), the primary sector was characterized by extraction and silviculture. The State has a savanna area of approximately 1,000,000 hectares, of which, it is estimated that 400,000 hectares can be considered potentially conducive to agriculture. As of 2013, rural producers entered the market due to the expansion of soy production in Amazonia. Eight years after the beginning of this process, the year 2021 appears to represent the greatest challenge for the continuation of activities, due to the deepening of the land and environmental imbroglio that involves the sector, with administrative, legal, and police developments. Most rural producers do not have an environmental license that authorizes them to carry out the preparations for the beginning of cultivation. Thus, this year's production is seriously compromised. There is a context of legal uncertainty, which consolidates the environment of uncertainties detrimental to the development of production. This article aims to analyze the causes of the plastering situation in the sector, as well as to explore possible scenarios arising from this context.

Keywords: rural development, institutions, land policy, environmental policy.

\section{Introdução}

Em tempos recentes, é possível localizar os problemas fundiários do Amapá a partir da criação do Território Federal, em 1943, processo resultante do desmembramento de partes das terras pertencentes ao estado do Pará, quando a política fundiária do território passou a ser de competência da União. 
Para melhor compreensão sobre a execução da política fundiária regional, destaca-se a existência de dois momentos na história da política econômica na Amazônia com importantes reflexos sobre a gestão de terras:

1) antes da emergência dos problemas ambientais, que vai até a década de 1980, período caracterizado pelo estímulo governamental à ocupação produtiva da região;

2) após a emergência dos problemas ambientais, a partir da década de 1980, etapa em que a legislação ambiental passou a restringir a execução de projetos econômicos, posto que surgiu o compromisso brasileiro com a preservação da Amazônia.

A questão ambiental passou a influenciar fortemente a política fundiária na região. Este marco temporal coincide, inclusive, com o período em que o Amapá foi Território Federal (até 1988) e a sua transformação em estado membro da União (a partir de 1988).

O Amapá possui uma economia incipiente, fortemente dependente das transferências governamentais. O PIB do estado atingiu o valor de 16,80 bilhões de reais em 2018 (Brasil, 2018b), correspondendo a tão somente $0,2 \%$ do PIB brasileiro. A partir da análise nas contas estaduais, observa-se a seguinte contribuição por setor: agropecuária (1,8\%), indústria (11,7\%) e serviços (86,5\%). No setor de serviços, a administração pública correspondeu a 45,9\% (Brasil, 2018b). Assim, percebe-se uma insignificante participação do setor produtivo na composição da economia estadual.

A partir do início da década passada, registrou-se o ingresso de produtores rurais oriundos de outras regiões do país no processo de avanço da ocupação da fronteira agrícola na Amazônia. Durante mais de cinco anos, a produção de grãos passou a representar uma expectativa de dinamismo no setor rural com possibilidades de aquecer e estimular outros segmentos, como a produção de ração, e, a partir daí, a piscicultura, a suinocultura e a avicultura, bem como outras atividades que se pudessem vincular à Zona Franca Verde de Macapá e Santana.

Entretanto, questões referentes aos históricos problemas fundiários do Amapá, aliadas a fatos relativos ao licenciamento ambiental, provenientes de erros da legislação estadual e delitos praticados dentro da estrutura administrativa, em conluio com alguns produtores, passaram a se constituir em graves episódios. Tais acontecimentos acabaram por alimentar um ambiente institucional adverso ao desenvolvimento da atividade, o que se agravou no decorrer dos anos seguintes.

O nascente sistema produtivo experimenta, na atualidade, um considerável definhamento, cujas causas foram analisadas nesta pesquisa, objetivando descrever a situação-problema, qual seja, a dificuldade em se produzir grãos em áreas apropriadas para agricultura, na Amazônia. Pelas razões expostas acima, mas principalmente pelas distorcidas e pré-concebidas visões que existem a respeito da região, que impedem uma compreensão integral da realidade e prejudicam não somente o desenvolvimento, mas também a preservação dos ecossistemas regionais.

\section{A recente expansão do cultivo de grãos no Amapá}

Até o ano de 2012, era praticamente inexistente a produção de grãos no Amapá, com exceção de um projeto-piloto de 100 ha experimentado no ano de 2004, mas que não evoluiu por conta de diversas dificuldades ${ }^{1}$. Apesar de já pré-existentes os atrativos naturais, como clima adequado, bom regime hídrico, áreas de cerrado aparentemente disponíveis, proximidade da fazenda com o porto e do porto com os grandes mercados consumidores internacionais, tais fatores demonstravam-se insuficientes para atrair investidores do segmento.

1 Para mais detalhes sobre a introdução do cultivo de grãos no Amapá, particularmente da soja (Chelala \& Chelala, 2019a). 
O fato que transforma esse cenário foi a inserção do Amapá na cadeia logística global, a partir da implantação em 2016 do projeto CIANPORT no porto de Santana, que instalou três silos com capacidade para armazenar 54 mil toneladas de grãos e movimentar 1,8 milhão de toneladas anuais². Tal movimento despertou a atenção para o Amapá e atraiu os primeiros produtores de soja, fazendo com que a área destinada ao cultivo de grãos saltasse de zero, em 2012, para aproximadamente 20 mil hectares em 2018, estagnando-se nesse patamar por dois anos e caindo em 2020, por conta dos gargalos abordados neste artigo.

A soja no Amapá se expande em direção ao cerrado, que ocupa quase um milhão de hectares do território do estado (aproximadamente $7 \%$ do total) e que possui efetivamente algo entre 200 e 400 mil hectares de áreas consideradas propícias para agricultura de escala (Amapá, 2016 e Chelala \& Chelala, 2019a). A Figura 1, a seguir, ilustra essa projeção de expansão.

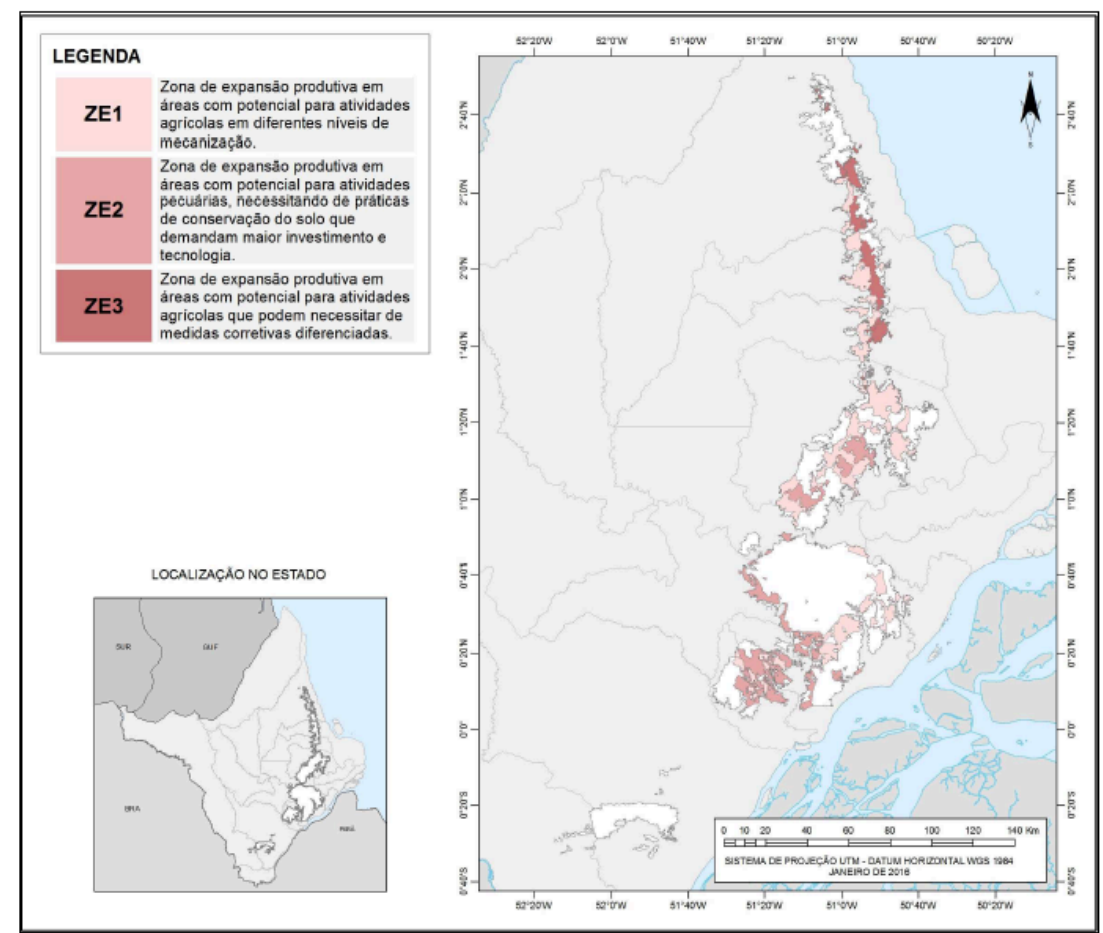

Figura 1. Áreas do cerrado amapaense destinadas à expansão da agricultura. Fonte: Zoneamento Socioambiental do Cerrado do Estado do Amapá (Amapá, 2016).

O mapa exposto na Figura 1 compõe a primeira aproximação de um zoneamento do cerrado do Amapá. Os polígonos classificados como ZE1 (tonalidade mais clara de rosa) foram considerados como áreas de expansão das atividades agrícolas e somam aproximadamente 193 mil hectares do cerrado amapaense.

No entanto, este estudo debruçou-se apenas sobre 721 mil hectares do cerrado, excluindo 249,3 mil hectares, que são propriedade da empresa Amapá Celulose (AMCEL), nos quais desenvolve-se um empreendimento de silvicultura de eucalipto destinado à cadeia produtiva do papel-celulose. A empresa cultiva em apenas 65 mil hectares, mantendo aproximadamente 185 mil hectares sem produção. Por essa razão, pode-se estimar em até algo em torno de 400 mil hectares a parcela do cerrado que pode ser considerada como propícia para a atividade

2 A Companhia Norte de Navegação e Portos (CIANPORT) foi constituída a partir da associação entre a AGROSOJA (Sorriso) e a FIAGRIL (Lucas do Rio Verde), e também prevê a construção de um terminal privativo e uma unidade industrial na llha de Santana, mas tal projeto está paralisado, sem data para prosseguir (Chelala \& Chelala, 2019b). 
agrícola (193 mil hectares do estudo citado somados aos 185 mil hectares da AMCEL sem cultivo de eucalipto).

A parcela deste minibioma - que não pertence à AMCEL e na qual estão implantados os atuais 20 mil hectares de fazendas de soja do Amapá - seria a área de expansão natural da produção, mas é nesta porção do espaço que se enfrentam as complexas dificuldades institucionais abordadas neste trabalho, além de alguma resistência do movimento ambientalista em geral, por se tratar, em alguma medida, de áreas de cerrado nativo.

Por outro lado, as terras pertencentes à AMCEL podem ter destinação à cultura de grãos, sendo que a empresa já tenciona implantar um projeto-piloto de plantio de soja, além de ter havido negociações com investidores interessados em adquirir ou arrendar parte da propriedade da empresa para projetos de agricultura de grãos. Entretanto, essas movimentações ainda são incipientes, tanto na produção própria quanto na que viria a ser realizada por terceiros.

\section{Histórico de problemas fundiários e ambientais no Amapá}

No período do Território Federal, a ação do poder público foi de induzir a ocupação produtiva da região. Instalou-se, em 1957, o primeiro grande projeto mineral da Amazônia, para exploração das jazidas de manganês pela Indústria e Comércio de Minérios S.A., assim como também dois grandes projetos de silvicultura, executados pela Jari Florestal e Agropecuária, em 1967, e pela Amapá Florestal e Celulose, em 1976. Existiram também outros projetos de menor dimensão.

Referente à questão fundiária, destaca-se que, no decorrer dos 45 anos em que o Amapá foi Território Federal, apesar da expectativa, a gestão das terras caracterizou-se pelo descaso. Jorge (2003) observa que, em um período de 23 anos, o Instituto Nacional de Colonização e Reforma Agrária (INCRA) arrecadou e discriminou 67,02\% da área do Território. Em todas essas ações, só foram reconhecidas potencialmente como terras de particulares 291.576 hectares, ou seja, 2,03\% da área total.

A partir da elevação do Amapá à categoria de estado membro da União, em 1988, estruturouse um novo arranjo institucional objetivando tratar das questões fundiárias, que se seguiu à promulgação da Constituição do Estado do Amapá, em 1991 (Constituição Estadual do Amapá, 1991). No decorrer de 32 anos, o que se observou foi a edição de um emaranhado de dispositivos legais, incapazes de solucionar os problemas relativos à regularização fundiária no Amapá.

A gestão das terras, no estado, transformou-se em um tema confuso e contraditório. Se, por um lado, registra-se imensa dificuldade para a regularização de áreas para utilização produtiva, por outro lado, destaca-se que não existiram empecilhos quando a decisão governamental se vinculou à criação de áreas protegidas no Amapá.

O estado possui $72 \%$ de sua área com algum tipo de proteção legal, entre unidades de conservação, quilombos e terras indígenas. O auge da execução dessas políticas foi a criação do Parque Nacional Montanhas do Tumucumaque, em agosto de 2002, com cerca de 3,85 milhões de hectares, o que corresponde a $27,21 \%$ da área do estado. O Parque foi criado sem a realização de qualquer tipo de consulta pública, em flagrante descumprimento à Lei n. ${ }^{\circ} 9.985 / 2000$, que instituiu o Sistema Nacional de Unidades de Conservação da Natureza (SNUC). E, note-se, com quase nenhuma reação sobre a decisão do governo federal, a criação desse parque representou um grande impacto para a gestão das terras do estado.

No que diz respeito à garantia de acesso às terras urbanas e rurais, a política fundiária do Amapá concentrou-se, principalmente nas duas últimas décadas, na tentativa de uma solução legal que definisse a possibilidade de regularização fundiária para o ordenamento territorial, inclusive, para fins de ocupação produtiva. Tal situação tornou-se ainda mais premente com o início do cultivo de grãos no cerrado amapaense, registrado a partir do ano de 2013. 
Para uma melhor compreensão a respeito do processo de condução das políticas públicas que concorreram para a conformação do atual imbróglio fundiário no Amapá, esquematizouse na Tabela 1, a seguir, a legislação relacionada, assim como também a criação/extinção das instituições encarregadas da execução da política fundiária, durante o período em análise.

Tabela 1. Cronologia da legislação e das políticas fundiárias

1943 Decreto-lei n. ${ }^{\circ}$ 5.812, de 13/09/1943 - Criação do Território Federal do Amapá, a partir do desmembramento de parte das terras pertencentes ao estado do Pará. (Brasil, 1943)

Divisão de Terras e Colonização (DTC), instituição responsável pela organização dos registros de terras para a colonização e o assentamento dos colonos. Criada pelo Decreto n. ${ }^{\circ} 4.438 / 1939$. (Brasil, 1939)

1970 Decreto-lei n. ${ }^{\circ}$ 1.110/1970 - Cria o Instituto Nacional de Colonização e Reforma Agrária (INCRA) e extingue o Instituto Brasileiro de Reforma Agrária (IBRA) e o Instituto Nacional de Desenvolvimento Agrário (INDA). (Brasil, 1970)

1973 Criação do Projeto Fundiário do Amapá, em 21/08/1973 - O INCRA passou a administrar parte das terras do Território.

1979 Lei Federal n. ${ }^{\circ}$ 6.739, de 05 de dezembro de 1979 - Definiu que os títulos das posses ou outros documentos que justificassem a ocupação concedidos legalmente pelo poder público teriam efeitos atribuídos pela legislação da época de suas expedições, no caso, a Lei n. ${ }^{\circ} 748$, de 25/02/1901. (Brasil, 1979) Transformação do Território Federal do Amapá em estado da federação brasileira, com a promulgação da Constituição Federal.

1989 Criação da Coordenadoria Estadual de Terras do Amapá (COTERRAS).

1991 Promulgação da Constituição do Estado do Amapá, que conferiu, formalmente ao estado, autonomia para formular, planejar e executar a sua política fundiária.

Decreto Estadual n. ${ }^{\circ}$ 0214, de 31/10/1991 - Cria o Instituto de Terras do Amapá (TERRAP). (Brasil, 1991)

2001 Lei Federal n. ${ }^{\circ}$ 10.304, de 05/11/2001 - Transferiu ao domínio dos estados de Roraima e Amapá terras pertencentes à União e deu outras providências. (Brasil, 2001)

2007 Decreto Federal n. ${ }^{\circ}$ 6.291, 07/12/2007 - Transfere gratuitamente ao domínio do estado do Amapá terras pertencentes à União. (Brasil, 2007)

2008 Lei Estadual n. ${ }^{0} 1.184$, de 04/01/2008 - o Instituto de Terras do Amapá (TERRAP), criado pelo Decreto n. ${ }^{\circ} 0214$, de 31 de outubro de 1991, passa a denominar-se Instituto do Meio Ambiente e de Ordenamento Territorial do Estado do Amapá (IMAP) e sua vinculação fica transferida para a Secretaria de Estado do Meio Ambiente. (Brasil, 2008)

2009 Lei Federal n. ${ }^{\circ} 11.949$, de 17/06/2009 substituiu o Decreto n. ${ }^{\circ} 6.291$, 07/12/2007 - Transferiu, ao domínio dos estados de Roraima e do Amapá, as terras pertencentes à União e deu outras providências. (Brasil, 2009)

2014 Supremo Tribunal Federal (STF) decide em desfavor dos estados de Roraima e do Amapá, em que não houve transferência automática aos estados das terras formadoras dos ex-Territórios Federais.

2016 Decreto Federal n. ${ }^{\circ} 8.713$, de 15/04/2016 - Regulamentou a Lei n. ${ }^{\circ} 10.304$, de 05/11/2001, no que se refere à transferência ao domínio do estado do Amapá de terras pertencentes à União. (Brasil, 2016a)

2017 Lei Federal n. ${ }^{\circ} 13.465$, de 11/07/2017 dispõe sobre novas regras para a regulamentação fundiária das terras da União localizadas na Amazônia Legal. (Brasil, 2017)

2018 Lei Complementar n. ${ }^{\circ} 110$, de 15/01/2018 - Dispõe sobre as terras públicas e devolutas do estado do Amapá, disciplina sua ocupação e dá outras providências. (Brasil, 2018a)

Fonte: Elaboração própria. 
Tabela 1. Continuação...

2019 O Governo do estado do Amapá assinou, em 30/01/2019, convênio com o Exército Brasileiro para realização do georreferenciamento de glebas e lotes urbanos e rurais.

Lei Estadual n. ${ }^{\circ} 2.425$, de 15/07/2019 - Cria o Instituto de Terras do Estado do Amapá (AMAPÁ TERRAS) e extingue o Instituto do Meio Ambiente e de Ordenamento Territorial do Estado do Amapá. (Brasil, 2019b)

Medida Provisória n. ${ }^{\circ}$ 901, de 18/10/2019 - Alterou a Lei n. ${ }^{\circ} 10.304$, de 05/11/2001, que transferiu, ao domínio dos estados de Roraima e do Amapá, terras pertencentes à União. (Brasil, 2019c)

Medida Provisória n. ${ }^{\circ}$ 910, de 10 de dezembro de 2019 - Altera a Lei n. ${ }^{\circ} 11.952$, de 25 de junho de 2009, que dispõe sobre a regularização fundiária das ocupações incidentes em terras situadas em áreas da União, a Lei n. ${ }^{\circ} 8.666$, de 21 de junho de 1993, que institui normas para licitações e contratos da administração pública, e a Lei n. ${ }^{\circ} 6.015$, de 31 de dezembro de 1973, que dispõe sobre os registros públicos. (Brasil, 2019d). Vigência encerrada em 20/05/2020. Decreto Federal n. ${ }^{\circ} 10.081$, de 25/10/2019 - Regulamentando a MP 901, de 18/10/2019 - A MP teve sua vigência encerrada em 29/03/2020. (Brasil, 2019a)

2020 Lei Federal n. ${ }^{\circ} 14.004$, de 26/05/2020 - Altera a Lei n. ${ }^{\circ} 6.634$, de 2 de maio de 1979, que dispõe sobre a Faixa de Fronteira, e a Lei n. ${ }^{\circ} 10.304$, de 5 de novembro de 2001, que transfere, ao domínio dos estados de Roraima e do Amapá, terras pertencentes à União. (Brasil, 2020b)

Decreto Federal n. ${ }^{\circ} 10.592$, de 24/12/2020 - Regulamenta a Lei n. ${ }^{\circ} 11.952$, de 25 de junho de 2009, para dispor sobre a regularização fundiária das áreas rurais situadas em terras da União, no âmbito da Amazônia Legal, e em terras do Instituto Nacional de Colonização e Reforma Agrária, por meio de alienação e concessão de direito real de uso de imóveis. (Brasil, 2020a)

Fonte: Elaboração própria.

Destaca-se que a Lei n. ${ }^{0} 10.304$, de 05/11/2001 (Brasil, 2001), o Decreto n. ${ }^{\circ} 6.291$, de 07/12/2007 (Brasil, 2007), a Lei n. ${ }^{0}$ 11.949, de 17/06/2009 (Brasil, 2009) e a Medida Provisória n. ${ }^{\circ}$ 901, de 18/01/2019 (Brasil, 2019c) possuem, em comum, o mesmo objetivo, isto é, "transferir ao domínio (...) do Amapá terras pertencentes à União". A edição desses dispositivos legais representou mera formalidade, não resolvendo a questão, cujo problema se arrasta por décadas ${ }^{3}$.

A expectativa de resolução da questão, na atualidade, está assentada na promulgação da Lei Federal n. ${ }^{\circ}$ 14.004, de 26/05/2020 (Brasil, 2020b), outra lei que mais uma vez transfere ao domínio dos estados de Roraima e do Amapá terras pertencentes à União. Desta feita, estabelece, em seu $\S 4^{\circ}$ prazo de 01 (um) ano para que a União identifique as áreas de exclusão, sob pena de presunção de validade, para todos os efeitos legais, das identificações dos destaques constantes da base cartográfica do Instituto Nacional de Colonização e Reforma Agrária (Brasil, 2020b) .

Não fosse isso o bastante, a política do governo Bolsonaro para a região amazônica é de absoluto descaso com a preservação das florestas, o que gera perplexidade. Os dois primeiros anos do governo foram de grande esforço de "passar a boiada"5 na região, causando um recrudescimento na atuação dos agentes públicos responsáveis pelos licenciamentos, pela

${ }^{3}$ A constatação da ineficácia da Lei 10.304, do Decreto 6.291, da Lei 11.949 e da MP 901 revela que o diploma legal é, por si, insuficiente para garantir que os objetivos almejados pelo legislador alcancem êxito. Fatores outros, como falta da estrutura do aparato fundiário local, incapacidade de superar as lacunas e pontos obscuros nas novas legislações, dentre outros, têm sido obstáculos instransponíveis para a efetividade da transferência de terras da União para o estado do Amapá.

${ }^{4}$ É relevante registrar que, em 24/12/2018, foi emitida pelo Cartório de Imóveis de $1^{\circ}$ Ofício Eloy Nunes, a matrícula de n. ${ }^{\circ}$ 57.519, denominada "Gleba Ad-04" (ou Matapi II), com 411,5 mil hectares. Há interpretações de que o prazo de um ano ao qual a Lei 14.004 se refere já se aplica a essa área registrada em cartório. Logo, já teria expirado o direito da União em contestá-la.

5 "Passar a boiada" foi a expressão utilizada pelo Ministro do Meio Ambiente Ricardo Salles, na reunião ministerial do dia 26/04/2020, com o intento de promover mudanças na regulamentação ambiental brasileira quando as atenções da imprensa, segundo ele, estavam focadas na cobertura da pandemia causada pelo novo coronavírus. 
fiscalização e pelo monitoramento das atividades econômicas. Somam-se a todas as questões destacadas sobre o confuso arcabouço legal, os problemas judiciais relacionados à existência da prática de delitos para obtenção da posse e propriedade da terra, o que será abordado mais à frente.

\section{Fundamentação Teórica}

A partir de meados do século passado, a teoria econômica incorporou uma análise explicativa cujo método saiu unicamente do foco do acúmulo de capital em direção a um entendimento mais complexo das variáveis que tornam o desenvolvimento possível. A teoria do desenvolvimento começou a se desviar do "fundamentalismo do capital", primeiramente enfatizando a "tecnologia" e, posteriormente, o papel de ideias que, de forma mais geral e final, enfocam as "instituições" (Evans, 2003).

As análises sobre o desempenho econômico de uma sociedade perpassam as variáveis relacionadas à reprodução do capital e ao desenvolvimento tecnológico. Para North (2018), as regras do jogo, isto é, a estrutura institucional, são os indutores ou os inibidores das atividades. Sob este prisma, a relação existente entre as instituições e o desempenho econômico é de causalidade, posto que são as regras que elevam ou reduzem os níveis de incerteza no ambiente de negócios. Quanto mais estáveis forem as instituições, menores serão os custos de transação, posto que as regras estão pré-estabelecidas e as possíveis mudanças não alterarão significativamente as relações entre os agentes econômicos. Evans (2003) propõe o que considera como uma teoria mais sofisticada de desenvolvimento, que traz a noção de "desenvolvimento deliberativo", enfatizando o papel das instituições no processo. Neste contexto, a mera existência dos fatores de produção da teoria econômica clássica não é suficiente para o entendimento das razões do crescimento econômico.

O segredo para atingir o crescimento econômico está na construção de uma matriz institucional que estimule a acumulação de capital físico e humano. A grande distância observada ainda hoje entre países pobres e ricos encontra-se muito mais em diferenças entre matrizes institucionais do que em problemas de acesso a tecnologias (Gala, 2003).

Em muitos países em desenvolvimento, as oportunidades para os empreendedores políticos e econômicos ainda são uma mistura heterogênea, mas, em sua grande maioria, favorecem atividades que promovem práticas redistributivas em vez de produtivas, que criam monopólios em vez de condições competitivas e que restringem as oportunidades em vez de ampliá-las (North, 2018).

O debate sobre desenvolvimento em áreas amazônicas é um tema que suscita posicionamentos, por vezes baseados em visões pré-concebidas, capazes de provocar manifestações acirradas que pouco contribuem para o equacionamento da dívida social crescente e das potencialidades econômicas e ambientais existentes na região. Algumas dessas visões estão assentadas no desconhecimento do conjunto das peculiaridades regionais, entretanto, acabam sendo apropriadas pelo senso comum e pela institucionalidade, a qual se relaciona com o setor de investimentos produtivos. Possivelmente sejam essas formas de pensamento fruto do caótico padrão de ocupação do território e das terras agrícolas, que tem sido a marca do último meio século, especialmente nas regiões Centro-Oeste e Norte (Navarro, 2001).

O modelo de ocupação econômica que norteou a Operação Amazônia, a partir de meados do século passado, certamente representa a origem de grande parte dos atuais problemas regionais, nos âmbitos ambientais, econômicos e sociais. As lições do passado se constituem em um importante aprendizado dos erros que não podem mais ser cometidos. Entretanto, o mau desenvolvimento não se combate com nenhum desenvolvimento. Inclusive, pelo fato 
de que, para que se possam promover políticas de preservação da Amazônia, é indispensável pensar nas políticas de desenvolvimento regional.

Homma et al. (2020) esclarecem que, embora persista uma nítida diversidade sociocultural e heterogeneidade econômico-produtiva no interior da região, em inúmeras esferas, comumente têm sido oferecidas grandiosas adjetivações para designar toda a Amazônia, como se esta fosse única e homogênea, apesar de haver um esforço político, acadêmico, científico e econômico para demonstrar o contrário.

\section{Referencial Metodológico}

A presente pesquisa está calcada em uma análise descritiva e exploratória, iniciada por meio de um levantamento aprofundado sobre a legislação fundiária e ambiental que constituiu o arcabouço normativo, a partir da criação do Território Federal do Amapá. Observa-se que, com o desmembramento das terras que antes pertenciam ao estado do Pará, os problemas fundiários foram transferidos. Entretanto, o Amapá não possuía autonomia para encaminhar a resolução da questão, fato que significou a edição de legislações e o estabelecimento de políticas públicas que não tiveram o condão de equacionar o problema desde aquele período até os dias atuais.

A emergência das questões ambientais foi outro fato que repercutiu no percurso metodológico, posto que se passou a analisar a legislação ambiental brasileira e as políticas públicas do governo federal para o Amapá, no período em que este ente federativo foi promovido à categoria de estado-membro da União, bem como passou-se também a realizar o exame da documentação relativa à criação do aparato institucional e legal amapaense, em observância ao novo contexto ambiental.

Utilizou-se a observação participante para acompanhar o processo de ingresso dos produtores de grãos no Amapá, caracterizando mais uma etapa de expansão da fronteira agrícola na Amazônia. Este movimento, por quase uma década, causou relativo dinamismo econômico, verificado na balança comercial do estado, mas com consequências negativas em ações das instituições de fiscalização, controle e repressão. Por razões metodológicas, a análise esteve circunscrita às investigações levadas a efeito pelos órgãos federais. Com isso, as Operações da Polícia Federal e as peças do Ministério Público Federal foram fundamentais para a compreensão do contexto que se pretendeu examinar.

Este é um campo recém-abordado e, portanto, os desdobramentos seguintes contribuirão para a compreensão que enriquecerá as análises e os estudos futuros. A pesquisa se baseou essencialmente na análise de documentos, livros, artigos, leis, projetos de lei, ações diretas de inconstitucionalidade e comunicados nos sites das instituições federais.

\section{Resultados e Discussão}

\subsection{A Licença Ambiental Única}

A arquitetura da legislação ambiental do Amapá se iniciou com a promulgação do Código Ambiental consubstanciado pela Lei Complementar n. ${ }^{\circ} 0005$, de 18 de agosto de 1994, à qual se seguiram a Lei da Biodiversidade do Amapá (Brasil, 1997), a Lei de Recursos Hídricos (Brasil, 2002a), Lei da Política Estadual de Florestas (Brasil, 2002b), dentre outras. 
No ano de 2012, o estado resolveu promover alteração na legislação ambiental, instituindo, no processo de licenciamento, a Licença Ambiental Única (LAU), por meio da Lei Complementar n. ${ }^{\circ} 70$ de 01/01/2012. Conforme definido na lei, a LAU podia ser concedida exclusivamente para as atividades e os empreendimentos pertencentes às tipologias do agronegócio, tais como agricultura, pecuária, avicultura, suinocultura, aquicultura, extrativismo, além de atividades agroindustriais e atividades das tipologias agroindustriais, que podem ser desenvolvidas em separado ou conjuntamente (Brasil, 2012). A validade da LAU foi definida entre quatro e seis anos.

Os processos de licenciamento e autorizações para intervenção ambiental de empreendimentos ou atividades no estado do Amapá passaram a dispor dos seguintes instrumentos: 1) Autorização Ambiental (AA); 2) Autorização para uso alternativo do solo; 3) Licença Ambiental Única (LAU); 4) Licença Prévia (LP); 5) Licença de Instalação (LI); 6) Licença de Operação (LO); 7) Declaração de Dispensa; 8) Revalidação de LO (Brasil, 2018c).

O intuito da lei que instituiu a LAU era simplificar o processo de licenciamento das referidas atividades. A simplificação do licenciamento ambiental, inclusive, tem sido objeto crescente de debate no Brasil. É um tema bastante controverso, mas com algum nível de razoabilidade, quando se busca corrigir distorções da lei federal, especialmente quando o diploma legal define o licenciamento trifásico (LP, LI e LO) para empreendimentos de portes distintos ou com potenciais poluidores não equivalentes.

Chama a atenção, no texto da lei que instituiu a LAU, não haver nenhuma menção aos procedimentos que deverão ser adotados quando o projeto implicar em necessidade de supressão vegetal nativa, em descumprimento daquilo que assinala a legislação federal. Muito embora o intuito do legislador fosse simplificar o processo, este aspecto deveria ter sido rigorosamente observado por duas razões principais: 1) por ser tratar de atividades do agronegócio e agroindustriais, e, portanto, com direta relação de utilização dos recursos naturais, e 2) para respeitar a legislação federal, cuja exigência, nesse caso, está expressa.

No período de três anos (2012-2015), as licenças ambientais para a produção de grãos foram expedidas em conformidade com o disposto na lei estadual vigente. Este é um período, inclusive, de aumento no ingresso de produtores rurais, assim como também da produção de grãos no estado. Em 2016, foi realizado o simbólico primeiro embarque ${ }^{6}$ da soja amapaense para exportação, demonstrando que a ocupação produtiva do cerrado vinha experimentando um efetivo processo de expansão.

Naquele mesmo ano, a LAU foi contestada pela Procuradoria Geral da República (PGR) por meio de uma Ação Direta de Inconstitucionalidade (ADI) ao Supremo Tribunal Federal (STF), com fulcro no artigo 12, inciso IV, parágrafo $7^{\circ}$, da Lei Complementar 5/1994, alterada pela Lei Complementar 70/2012 (Brasil, 2012), que, de acordo com a PGR, violava competência privativa da União para legislar sobre proteção ao meio ambiente. A PGR defendeu que a LAU, além de alijar licenças ambientais específicas, extinguia etapas do processo de avaliação para deferimento de licença no caso de obras e empreendimentos (Brasil, 2016b)7.

A omissão do legislador em não exigir autorização para supressão vegetal nativa, quando da elaboração da LAU, constituiu-se na origem de um dos problemas enfrentados pelos produtores rurais, com desdobramentos administrativos, judiciais e policiais.

Em 2017, o Instituto Brasileiro do Meio Ambiente e dos Recursos Renováveis (IBAMA) detectou uma região onde havia sido realizada uma considerável supressão vegetal, que não possuía autorização correspondente no Sistema Nacional do Meio Ambiente (SISNAMA).

\footnotetext{
${ }^{6}$ No dia 08/09/2016, os produtores rurais promoveram um evento na Companhia Docas de Santana, para comemorar o primeiro embarque da soja amapaense para a exportação. O evento contou com a participação de autoridades locais, da imprensa e de convidados.

7 A PGR obteve êxito em sua demanda junto ao STF, como será demonstrado no próximo item deste artigo.
} 
A partir da fiscalização in loco, foi confirmada a inexistência de tais autorizações para supressão vegetal. O IBAMA, com isso, autuou os proprietários das áreas e, em seguida, as embargou. As áreas embargadas somaram 8.633,71 hectares de um total de 18.900 hectares de áreas plantadas. Naquele ano, os produtores rurais só conseguiram exportar a soja por meio de uma liminar da justiça federal (Chelala \& Chelala, 2018a). O IBAMA recorreu ao Superior Tribunal de Justiça (STJ) e a batalha judicial acabou produzindo uma série de outras ações com o envolvimento de outras instituições federais, conforme será abordado em seguida.

\subsection{A Operação Shoyu e a reestruturação dos órgãos ambientais e fundiários do estado do Amapá}

No dia 14/02/2019, a Polícia Federal deflagrou a "Operação Shoyu” com o objetivo de investigar possíveis irregularidades no processo de licenciamento ambiental relacionadas à produção de soja no Amapá, especialmente às multas ambientais aplicadas pelo IBAMA. O presidente 0 Instituto do Meio Ambiente e Ordenamento Territorial do Estado do Amapá (IMAP) foi preso. Além disso, foram expedidos um mandado de afastamento de função pública e 18 mandados de busca e apreensão. De acordo com a assessoria de comunicação da Polícia Federal, havia um esquema de substituição das multas aplicadas pelo IBAMA por multas aplicadas pelo órgão ambiental estadual, o IMAP, em valores menores e sem que houvesse fiscalização in loco.

Meses depois, em maio de 2019, a Procuradoria Geral da República (PGR) constituiu uma Força-Tarefa, denominada "Estado do Amapá", cuja finalidade era investigar possíveis esquemas de corrupção no estado (Brasil, 2019e). As ações desta Força-Tarefa tinham objetivo de identificar possíveis organizações criminosas cuja relação com o poder público tivesse o propósito de obter vantagens ilícitas, assim como também prevenir a ocorrência de crimes ambientais. A necessidade de criação da Força-Tarefa, segundo o MPF, foi uma consequência dos desdobramentos advindos de três operações policiais: Terras Caídas, Miríade e Shoyu.

Em abril de 2020, o STF decidiu por meio do Acórdão de 20/04/2020 que "o art. 12, IV e $\S 7^{\circ}$, da Lei Complementar 5/1994, com redação conferida pela Lei Complementar 70/2012, não poderia ter instituído licença ambiental que substitua e dispense as licenças ambientais exigidas pela legislação federal nem afastar exigência de estudo prévio de impacto ambiental". O documento destaca que: "ao fazê-lo, a norma estadual usurpou competência privativa da União para legislar sobre normas gerais em matéria de proteção ambiental. Deve, portanto, ser declarada inconstitucionalidade formal dos dispositivos" (Monteiro, 2020). Nesse passo, todas as licenças ambientais expedidas para os produtores de grãos do Amapá foram canceladas. A decisão do STF, contudo, não acarretou prejuízos para a safra de 2020, muito embora a partir daí seria necessário iniciar um novo processo de licenciamento ambiental, desta feita em observância às normas federais vigentes.

Adicionalmente à decisão do STF, em maio de 2020, a Polícia Federal deflagrou quatro operaçães (segunda fase da Operação Shoyu, Operação Imisção, Operação Premonição e Operação (onchavo) com o objetivo de desarticular organização criminosa com atuação em grilagem de terras, regularização fundiária e licenciamentos ambientais ilegais, dentre outras práticas criminosas, no Amapá 8 . Registra-se que tais ações foram resultado de um trabalho conjunto com Ministério Público Federal, fruto da força-tarefa já citada.

A deflagração de sete ${ }^{9}$ operações policiais, a decisão do STF, bem como as reiteradas manifestações e recomendações do Ministério Público Federal, relacionadas com o

${ }^{8}$ Comunicação Social da Polícia Federal. Disponível em: http://www.pf.gov.br/

9 Operação Terras Caídas, Operação Miríade, Operação Shoyu, Operação Shoyu - $2^{2}$ fase, Operação Imisção, Operação Premonição e Operação Conchavo. 
desenvolvimento da produção de grãos no Amapá, desencadeou forte pressão sobre o executivo estadual, requisitando ações com o propósito de coibir uma rotina de práticas delituosas no interior do aparelho do estado. Com isso, o governo estadual resolveu promover uma reestruturação nos órgãos encarregados pelas questões fundiárias e ambientais no Amapá.

O IMAP, que era responsável pela execução da política de meio ambiente e gestão do espaço territorial estadual, foi extinto, e as atribuições relativas ao licenciamento ambiental voltaram para a Secretaria de Estado do Meio Ambiente (SEMA). A regularização fundiária ficou sob a incumbência do recém-criado Instituto de Terras do Amapá (Amapá Terras). Ademais, foram extintos o Instituto Estadual de Florestas (IEF) e a Agência de Pesca do Amapá (PESCAP). As atribuições desses órgãos foram distribuídas entre outras instâncias da administração estadual.

Além da reestruturação administrativa, aparentemente, o poder público estadual passou a analisar as demandas dos produtores rurais com cautela e desconfiança, tendo em vista a quantidade de supostos crimes que passaram a ser investigados pelos órgãos de fiscalização, controle e repressão.

\subsection{As controversas visões sobre regularização fundiária na Amazônia}

Conforme destacado acima, a ocupação produtiva da Amazônia passou a ser assunto de acalorados debates, a partir da intensificação do debate ambiental nas décadas de 1980 e 1990. Isto porque o projeto de desenvolvimento econômico levado a efeito pelos governos militares provocou grandes danos ambientais na região. Os Grandes Projetos mínero-metalúrgicos, agropecuários, florestais, bem como as obras de infraestrutura, com destaque para a construção da rodovia Belém-Brasília e as Usinas Hidrelétricas de Tucuruí e de Balbina são símbolos da política do governo federal que gerou grandes impactos ambientais na Amazônia, provocando forte reação no nascente movimento ambientalista brasileiro, o que passou a conformar uma distorcida ideia de que a principal política pública a ser adotada na Amazônia era a preservação.

Esta ideia assumiu dimensão internacional, especialmente com a intensificação dos conflitos socioambientais na região, culminando com o assassinato do líder seringueiro Chico Mendes, em Xapuri, no Acre, em dezembro de 1988.

Caracterizar a Amazônia apenas como a região das florestas tropicais não corresponde à sua realidade fisiográfica. A região abriga também porções de cerrado com aptidão para agricultura, amplamente evidenciadas em pesquisas e estudos da Empresa Brasileira de Pesquisa Agropecuária (EMBRAPA), em suas diversas unidades sediadas nos Estados amazônicos, bem como das instituições de pesquisa e as universidades da região. Entretanto, o discurso hegemônico assimilado mundial e nacionalmente é tão somente o de "preservação da Amazônia", como se a região fosse composta apenas pelas florestas ombrófilas tropicais, desconsiderando as peculiaridades dos ecossistemas regionais e a possibilidade de utilização produtiva das porções propícias para este fim, sem prejuízo da preservação das florestas que integram o bioma regional.

Esta é uma percepção superficial e linear, inadequada da Amazônia, na medida em que a região possui uma população estimada em 29 milhões de habitantes (Instituto Brasileiro de Geografia e Estatística, 2020), baixos indicadores sociais e o menor PIB do país, representando apenas 5,5\% do PIB nacional, o que é menor do que sua participação relativa na população do Brasil ( $8,7 \%$ dos habitantes), requisitando, por isso, políticas de desenvolvimento capazes de estimular a geração de renda e riqueza para essa população.

Essa percepção da região interfere fortemente sobre considerável parcela dos atuais projetos de desenvolvimento. Observa-se que as próprias instituições federais de regulação, 
controle e fiscalização, muitas vezes, se manifestam por meio de suas decisões, contrárias ao desenvolvimento econômico da região. É possível perceber isso a partir de análise documental de diversas decisões exaradas pelas autoridades públicas, destacadamente com questões relacionadas ao licenciamento ambiental e à regularização fundiária, imprescindíveis para a execução de projetos econômicos.

Neste estudo, dar-se-á destaque para uma Ação Direta de Inconstitucionalidade (ADI) firmada pela Força-Tarefa "Estado do Amapá", em resposta a uma controversa e equivocada decisão do governo federal de flexibilizar o processo de regularização fundiária no país. O que se busca evidenciar, neste contexto, é a forma como a Procuradoria da República no estado do Amapá construiu a justificativa para fazer a contraposição à ação do executivo federal.

Em dezembro de 2019, o governo federal editou a Medida Provisória (MP n. ${ }^{\circ}$ 910/2019) (Brasil, 2019d), alterando dispositivos sobre a regularização fundiária das ocupações incidentes em terras da União. A flexibilização do processo de regularização de terras causou reações de diversos grupos de interesse, especialmente da instituição encarregada de fiscalizar o cumprimento das leis.

Em janeiro de 2020, a Procuradoria da República no Estado do Amapá (PR-AP) encaminhou, à Procuraria Geral da República (PGR), documento propondo uma Ação Direta de Inconstitucionalidade (ADI), alegando que a referida MP representava uma afronta à função socioambiental da terra (Brasil, 2020d). Chama a atenção que a sustentação da PR-AP se baseia no trinômio: função social da propriedade, defesa do meio ambiente e redução das desigualdades regionais e sociais.

Referente à função social da propriedade perseguida pela PR-AP, observa-se que as terras do cerrado amapaense não estavam ocupadas quando do ingresso dos produtores rurais no Amapá. Uma vez que as terras se encontravam desocupadas, evidencia-se que não estavam cumprindo o seu papel social, portanto, seria interessante o esforço do poder público no sentido de estimular o cumprimento do artigo 170 inciso III, da CRFB-1988 (Constituição Brasileira, 1988). Alegar a necessidade de que as terras pertencentes ao cerrado amapaense cumpram a sua função social é buscar garantir a regularização fundiária para quem nela produz.

Outro ponto que se destaca é a defesa do meio ambiente. O documento da PR-AP vincula expressamente a regularização de terras na Amazônia, flexibilizada na MP n. ${ }^{\circ}$ 910/2019, ao desmatamento. Para tanto, fundamenta a sua tese em "opinião" de pesquisadores de uma instituição não governamental (Brasil, 2020d, p. 12), que não possui estudos relativos à situação do estado do Amapá.

Ao contrário do que aconteceu em outros espaços da região amazônica, no estado do Amapá, não existe relação entre a produção de grãos e o desmatamento. A Figura 2 expressa que, no período de 2013 a 2019, o desmatamento manteve-se em patamares reduzidos. Isto é, em seis anos de cultivo de soja no Amapá, não foi registrado, pelo INPE, aumento do desmatamento.

A elevação registrada no período de 2019 a 2020 não está relacionada à produção de grãos, uma vez que a abertura e expansão das fazendas produtoras de grão no Amapá se deu entre os anos de 2012 e 2017, tendo o total de área plantada se mantido inalterado desde então. Observa-se que este período de implantação dos projetos de agricultura extensiva no Amapá confunde-se justamente com os anos de menor taxa de desmatamento do estado. Portanto, quando a PR-AP destaca um trecho da ADI 4.269 invocando que as terras da Amazônia "são bens jurídicos de máxima importância" tuteladas pelo estado brasileiro, este pode ser verdadeiro quando a referência é feita à floresta amazônica, mas não parece razoável considerar que as áreas de cerrado se enquadrem nessa classificação, uma vez que a sua utilização produtiva não impacta na integridade das florestas. 


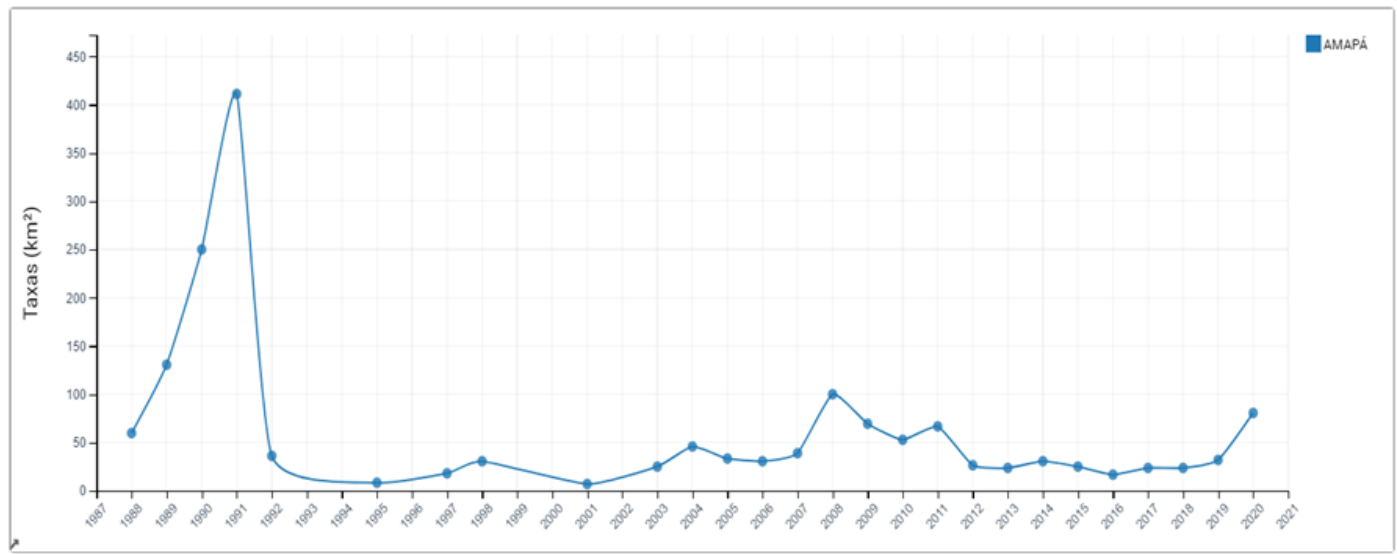

Figura 2. Taxa de desmatamento no Amapá (1988-2020).

Fonte: Instituto Nacional de Pesquisas Espaciais, 2020.

A análise do discurso sustentado pela Procuradoria da República no Estado do Amapá consolida-se no trecho constante do documento: "Nesse sentido, os privilégios legais para a prática de grilagem têm não somente impactos sociais (especialmente o avanço sobre terras tradicionalmente ocupadas), mas também ambientais (estímulo ao desmatamento para consolidar a posse)"(Brasil, 2020d). Conforme já abordado, esta justificativa não se sustenta se a tentativa foi retratar a realidade amapaense, posto que a produção de grãos não está em terras tradicionalmente ocupadas e sequer são causadoras de desmatamento no Amapá.

Por fim, a PG-AP invoca em sua justificativa a necessidade de redução das desigualdades regionais e sociais, revelando outra visão distorcida da situação, devido ao fato de o Amapá, por apresentar um definhado sistema produtivo, um dos menores PIB do país e elevadas taxas de desemprego, requisita, por tais motivos, estimular o ingresso de projetos econômicos, de modo a possibilitar a expansão de sua economia e a redução das desigualdades. É, portanto, justamente o oposto do que a PG-AP defende.

Adicionalmente, destaca-se que, em que pesem os delitos registrados no processo de regularização fundiária no Amapá, que estão sendo identificados e punidos, não parece ser adequado utilizar-se dos argumentos relativos ao desmatamento no Amapá, bem como às questões econômicas e sociais, associando-os em uma relação de causa e efeito, tornando-os como pretexto em decisões institucionais manifestadamente contrárias ao desenvolvimento da produção de grãos no cerrado amapaense. Tal posicionamento claramente é uma expressão das teses que defendem tão somente a preservação da região.

Em razão de ser uma proposta bastante controversa, a MP n. ${ }^{\circ}$ 910-2019, editada pelo governo federal, perdeu a validade, pelo fato de não ter ido à votação no Congresso Nacional. O governo federal encaminhou em substituição a MP, o Projeto de Lei (PL n. ${ }^{\circ}$ 2633/20), que se encontra em tramitação, mas que possui reduzidas possibilidades de ser aprovado em razão de prever grande flexibilização para a regularização fundiária no país. Dentre as principais críticas ao PL 2633/20, destacam-se: o aumento de risco de titulação de áreas sob conflito, ao ampliar para imóveis de até seis módulos fiscais a dispensa de vistoria presencial prévia à titulação (admitindo somente a fiscalização remota); a possibilidade de titular áreas que tenham sofrido desmatamento ilegal, caso não tenham sido autuadas anteriormente ao pedido de titulação, e a fragilização da fiscalização ambiental pós-titulação, uma vez que o detentor da propriedade pode manter-se no imóvel até dez anos após ter recebido o título, ainda que tenha praticado desmatamento ilegal na área (Brito, 2020). 
O PL n. ${ }^{\circ}$ 2633/20 tem gerado manifestações de ambientalistas, comunidades indígenas e quilombolas, defensores dos direitos humanos, inclusive reações internacionais, como documentos dos parlamentos inglês e alemão, informando que a sua aprovação pode comprometer as relações comerciais entre os países.

Evidencia-se, com isso, que o governo federal na gestão do presidente Jair Bolsonaro, conseguiu, com seu equivocado projeto de regularização fundiária, tornar ainda mais conturbado o processo em curso na Amazônia, com repercussões negativas para o estado do Amapá, aprofundando a polarização sobre as visões existentes sobre o desenvolvimento regional.

\section{Conclusões}

Douglas North (North, 2018) destaca que as regras do jogo, isto é, a estrutura institucional, são indutoras ou inibidoras das atividades econômicas. A relação que se estabelece entre as instituições e o desempenho econômico é de causalidade, posto que são as regras, o cumprimento das leis e a disposição dos agentes públicos que elevam ou reduzem os níveis de incerteza no ambiente de negócios. Quanto mais estáveis forem as instituições, menores serão os custos de transação (Chelala \& Chelala, 2018b).

Ao se buscar caracterizar a relação dos produtores de grãos do estado do Amapá, com a estrutura institucional existente, observa-se, na atualidade, uma situação de relativo isolamento. Os produtores rurais não possuem qualquer tipo de apoio por parte das instituições dotadas de competência de fomento e desenvolvimento. Além disso, despertam desconfiança das instituições encarregadas do licenciamento, controle e fiscalização.

A produção de grãos no Amapá aparenta, para grande parte das instituições, estar associada à criminalidade e isso não se refere somente à prática dos delitos investigados pelo Ministério Público Federal e pela Polícia Federal. A criminalização da produção de grãos no cerrado amapaense, para parcela dos agentes públicos, está vinculada ao desmatamento e à derrubada da floresta. Esta compreensão não corresponde à realidade. Observa-se que o IBAMA não autuou os produtores rurais por tais razões, mas pela ausência de autorização para supressão vegetal, razão distinta dos crimes ambientais que lhes são distorcidamente imputados.

Ante este cenário adverso, as atividades relacionadas à produção de grãos experimentam um contínuo cenário de insegurança jurídica. Alguns produtores rurais já deixaram o Amapá, abandonaram suas áreas e retornaram para os seus estados de origem. Os que ainda permanecem não possuem título de propriedade do imóvel rural que ocupam e valem-se de decisões jurídicas precárias sobre suas licenças ambientais para providenciar os preparativos para o início do cultivo da soja da safra 2021. Este contexto inviabiliza pensar em ampliação de investimentos para o setor. Ao contrário, sequer será mantida, em 2021, a mesma extensão de área plantada no ano de 2020, que foi de 19 mil hectares $^{10}$.

Tais condições poderão gerar impactos negativos na, já definhada, balança comercial do estado, mas, principalmente, sobre todos os agentes econômicos envolvidos direta e indiretamente com a produção de grãos: empresas de originação, produtores, transportadores, trabalhadores rurais, dentre outros.

O equacionamento do problema fundiário torna-se a principal questão dos produtores rurais para a resolução dos diversos entraves que obstaculizam o desenvolvimento da produção. Isto ocorre porque somente com o título de propriedade do imóvel será possível requerer a licença

${ }^{10}$ Até a data de conclusão deste artigo, dirigentes da APROSOJA estimavam uma área plantada ao redor de 4 mil hectares para o ano de 2021, ou seja, aproximadamente 20\% da área produtiva de 2020. 
ambiental em conformidade com a legislação federal e corrigir os equívocos do processo de licenciamento anterior ${ }^{11}$.

Para tanto, o que se vislumbra no horizonte em curto prazo é a possiblidade de cumprimento da Lei n. ${ }^{\circ}$ 14.004, de 26/05/2020, conforme já destacado, uma vez que a referida lei estabelece, em seu $§ 4^{\circ}$, o prazo de um ano, ou seja, até maio de 2021, para que a União identifique as áreas de exclusão, sob pena de presunção de validade, para todos os efeitos legais, das identificações dos destaques constantes da base cartográfica do INCRA. Caso a União não defina as áreas de seu interesse até aquele prazo, o estado poderá conduzir a regularização das áreas federais para o seu domínio e, após isso, proceder a regularização para particulares.

Contudo, somente o encerramento do prazo previsto na lei não será suficiente. As questões fundiárias não serão resolvidas automaticamente. As instituições estaduais poderão tomar a decisão de encaminhar o processo de regularização das terras dos produtores rurais, assim como também poderão decidir aguardar mais algum tempo. O poder público estadual poderá fazer, mas também poderá deixar de fazer. Foi aqui demonstrado que a postura dos órgãos estaduais de licenciamento ambiental e de regularização fundiária, pressionados pelas instituições de fiscalização, controle e repressão, tem se caracterizado por excessiva cautela e desconfiança, que beira a omissão, impossibilitando qualquer tipo de opção ao produtor de grãos que queira produzir de forma legalizada. Portanto, o cenário que se apresenta é de profunda insegurança jurídica e de continuação das dificuldades assinaladas.

Uma lição que se pode tirar deste grande imbróglio reside na condução equivocada sobre a forma com que o poder público encaminhou a questão fundiária na Amazônia, especialmente após a emergência dos problemas ambientais. Os imensos danos ambientais causados pelo formato com que os projetos econômicos foram desenvolvidos na região, no período dos governos militares, geraram uma percepção distorcida sobre produção agrícola em áreas da região amazônica.

Para determinados segmentos da sociedade, falar sobre agricultura empresarial na Amazônia é um despropósito. As políticas públicas coerentes para a região são a preservação, o extrativismo vegetal e a agricultura familiar. Apesar da grande importância de todas essas atividades, somente elas [ ? ] não são capazes de gerar dignas condições de vida para quase 30 milhões de habitantes.

Atividades produtivas de grande escala são vistas com bastante objeção por diversos segmentos sociais: representantes das ONGs, dos movimentos sociais, instituições religiosas, pesquisadores, imprensa e, principalmente, agentes e autoridades responsáveis pelas instituições públicas. E isso se pode observar nas manifestações dos órgãos de fiscalização quando realçam as disfunções provocadas pela agricultura empresarial na Amazônia sem o entendimento de que as atividades produtivas, quando realizadas em rigorosa observância à legislação ambiental, são necessárias e desejáveis. Narrativas nesse sentido são incompletas e distantes das urgentes demandas regionais. O sistema econômico precisa ser fortalecido e ampliado, de modo a inserir contingentes da população que vivem em condições muito precárias.

Pensar na preservação da floresta amazônica é considerar invariavelmente o desenvolvimento da região. Com a melhoria dos indicadores sociais, como saúde, educação, moradia, trabalho e renda, é possível haver condições de sensibilizar e envolver os seus habitantes nas diversas propostas que objetivam zelar pela integridade da floresta amazônica. Países que possuem elevados Índices de Desenvolvimento Humano (IDH) demonstram maior preocupação com os problemas ambientais, mas o mesmo não se verifica nos países pobres.

${ }^{11}$ Ressalvada a decisão da Justiça Estadual em caráter liminar para expedição de licenças provisórias a produtores que não possuem o documento comprobatório de posse, citada neste artigo. 
Por outro lado, evidencia-se o equívoco das políticas de flexibilização, redução e/ou extinção do aparato de proteção ambiental que estão sendo executadas na região. "Passar a boiada" certamente não é o caminho que se deva trilhar na construção dos projetos de sustentabilidade. A Amazônia tem sido duramente penalizada pelas políticas do governo do presidente Jair Bolsonaro, com nefastos desdobramentos regional e mundial.

Tanto a postura das instituições que condenam o desenvolvimento da agricultura empresarial na Amazônia quanto a postura do governo federal não são adequadas. Elas pouco contribuem para o encaminhamento de efetivas políticas de desenvolvimento sustentável. A proteção da Amazônia requisita necessariamente considerar o seu desenvolvimento e a consequente elevação da qualidade de vida dos habitantes da região.

O Amapá chegará à marca de um milhão de habitantes dentro de pouco tempo, ostentando de forma consistente baixos indicadores econômicos e sociais, e grande dependência dos programas de transferência de renda. De acordo com os dados da PNAD-COVID, o Amapá foi a unidade da federação que apresentou o maior índice de domicílios beneficiados com o Auxílio Emergencial no ano de 2020, o que significa $67,3 \%$ dos domicílios do estado. A crise sanitária da COVID-19 aumentou a situação de pobreza e as dificuldades agravam-se, ainda mais, quando os esforços para o desenvolvimento da economia encontram um ambiente institucional profundamente adverso.

\section{Referências}

Brasil. (1939). Decreto n 4.438, de 26 de julho de 1939. Cria a Divisão de Terras e Colonização - DTC, ligada ao Ministério da Agricultura. Cronologia da Questão Agrária Brasileira. Recuperado em 30 de dezembro de 2020, de https://www12.senado.leg.br/

Brasil. (1943). Decreto-lei n 5.812, de 13 de setembro de 1943. Cria os Territórios Federais do Amapá, do Rio Branco, do Guaporé, de Ponta Porã e do Iguassú. Recuperado em 29 de dezembro de 2020, de http://www.planalto.gov.br/

Brasil. (1970). Decreto-lei n 1.110, de 09 de julho de 1970. Cria o Instituto Nacional de Colonização e Reforma Agrária - INCRA, extingue o Instituto Brasileiro de Reforma Agrária, o Instituto Nacional de Desenvolvimento Agrário e o Grupo Executivo da Reforma Agrária e dá outras providências. Recuperado em 30 de dezembro de 2020, de http://www.planalto.gov.br

Brasil. (1979). Lei n 6.739, de 05 de dezembro de 1979. Dispõe sobre a matrícula e o registro de imóveis rurais e dá outras providências. Recuperado em 29 de dezembro de 2020, de http://www.planalto.gov.br/

Brasil. (1991). Decreto n 0214, de 31 de outubro de 1991. Cria o Instituto de Terras do Amapá - TERRAP. Recuperado em 29 de dezembro de 2020, de http://www.al.ap.gov.br/

Brasil. (1997). Lei no 0388, de 10 de dezembro de 1997. Dispõe sobre os instrumentos de controle do acesso à biodiversidade do Estado do Amapá e dá outras providências. Recuperado em 29 de dezembro de 2020, de http://www.al.ap.gov.br

Brasil. (2001). Lei n 10.304, de 05 de novembro de 2001. Transfere ao domínio dos Estados de Roraima e Amapá terras pertencentes à União e deu outras providências. Recuperado em 29 de dezembro de 2020, de http://www.planalto.gov.br/

Brasil. (2002a). Lei no 0686, de 07 de julho de 2002. Dispõe sobre a Política de Gerenciamento dos Recursos Hídricos do Estado do Amapá e dá outras providências. Recuperado em 29 de dezembro de 2020, de http://www.al.ap.gov.br 
Brasil. (2002b). Lei n 0702, de 28 de junho de 2002. Dispõe sobre a Política Estadual de Florestas e demais Formas de Vegetação do Estado do Amapá e dá outras providências. Recuperado em 29 de dezembro de 2020, de http://www.al.ap.gov.br

Brasil. (2007). Decreto n ${ }^{\circ} 6.291$, de 07 de novembro de 2007. Transfere gratuitamente ao domínio do Estado do Amapá terras pertencentes à União, nos termos do art. $5^{\circ}$ do Decreto-Lei $n^{\circ} 2.375$, de 24 de novembro de 1987, e dá outras providências. Recuperado em 29 de dezembro de 2020, de http://www.planalto.gov.br/

Brasil. (2008). Lei n 1.184, de 04 de janeiro de 2008. O Instituto de Terras do Amapá - TERRAP, criado pelo Decreto $n^{\circ}$. 0214, de 31 de outubro de 1991, passa a denominar-se, Instituto do Meio Ambiente e de Ordenamento Territorial do Estado do Amapá - IMAP e sua vinculação fica transferida para a Secretaria de Estado do Meio Ambiente. Recuperado em 29 de dezembro de 2020, de http://www.planalto.gov.br/

Brasil. (2009). Lei n 11.949, de 17 de julho de 2009. Dá nova redação à Lei no 10.304, de 5 de novembro de 2001, que transfere ao domínio dos Estados de Roraima e do Amapá as terras pertencentes à União e dá outras providências. Recuperado em 29 de dezembro de 2020, de http://www.planalto.gov.br/

Brasil. (2012). Lei complementar $n^{\circ} 70$, de $1^{\circ}$ de janeiro de 2012. Dá nova redação ao art. 12 da Lei Complementar $n^{\circ} 5$ de 18 de agosto de 1994 e dá outras providências. Recuperado em 29 de dezembro de 2020, de http://www.planalto.gov.br/

Brasil. (2016a). Decreto $n^{\circ}$ 8.713, de 15 de abril de 2016. Regulamenta a Lei $n^{\circ} 10.304$, de 5 de novembro de 2001, no que se refere à transferência ao domínio do Estado do Amapá de terras pertencentes à União. Recuperado em 29 de dezembro de 2020, de http://www. planalto.gov.br/

Brasil. (2017). Lei n 13.465, de 11 de julho de 2017. Dispõe sobre a regularização fundiária rural e urbana, sobre a liquidação de créditos concedidos aos assentados da reforma agrária e sobre a regularização fundiária no âmbito da Amazônia Legal; institui mecanismos para aprimorar a eficiência dos procedimentos de alienação de imóveis da União e dá outras providências. Recuperado em 29 de dezembro de 2020, de http://www.planalto.gov.br/

Brasil. (2018a). Lei Complementar n 110, de 15 de janeiro de 2018. Dispõe sobre as terras públicas e devolutas do Estado do Amapá, disciplina sua ocupação e dá outras providências. Recuperado em 29 de dezembro de 2020, de http://www.planalto.gov.br/

Brasil. (2019a). Decreto $n^{\circ} 10.081$, de 25 de outubro de 2019. Altera o Decreto $n^{\circ} 8.713$, de 15 de abril de 2016, que regulamenta a Lei no 10.304, de 5 de novembro de 2001, no que se refere à transferência ao domínio do Estado do Amapá de terras pertencentes à União. Recuperado em 29 de dezembro de 2020, de http://www.planalto.gov.br/

Brasil. (2019b). Lei n 2.425, de 15 de julho de 2019. Cria o Instituto de Terras do Estado do Amapá - AMAPÁ TERRAS e extingue o Instituto do Meio Ambiente e de Ordenamento Territorial do Estado do Amapá. Recuperado em 29 de dezembro de 2020, de http://www. planalto.gov.br/

Brasil. (2019c). Medida Provisória n 901, de 18 de outubro de 2019. Altera a Lei n.0 10.304, de 05.11.2001, que transfere ao domínio dos Estados de Roraima e do Amapá, terras pertencentes à União. Recuperado em 29 de dezembro de 2020, de http://www.planalto.gov.br/

Brasil. (2019d). Medida Provisória n 910, de 10 de dezembro de 2019. Altera a Lei n 11.952, de 25 de junho de 2009, que dispõe sobre a regularização fundiária das ocupações incidentes em terras situadas em áreas da União, a Lei nº 8.666, de 21 de junho de 1993, que institui 
normas para licitações e contratos da administração pública, e a Lei nº 6.015, de 31 de dezembro de 1973, que dispõe sobre os registros públicos. Recuperado em 29 de dezembro de 2020, de http://www.planalto.gov.br/

Brasil. (2020a). Decreto $n^{\circ} 10.592$, de 24 de dezembro de 2020. Regulamenta a Lei $n^{\circ} 11.952$, de 25 de junho de 2009, para dispor sobre a regularização fundiária das áreas rurais situadas em terras da União, no âmbito da Amazônia Legal, e em terras do Instituto Nacional de Colonização e Reforma Agrária, por meio de alienação e concessão de direito real de uso de imóveis. Recuperado em 29 de dezembro de 2020, de http://www.planalto.gov.br/

Brasil. (2020b). Lei n 14.004, de 26 de maio de 2020. Altera a Lei no 6.634, de 2 de maio de 1979, que dispõe sobre a Faixa de Fronteira, e a Lei n. 0 10.304, de 5 de novembro de 2001, que transfere ao domínio dos Estados de Roraima e do Amapá terras pertencentes à União. Recuperado em 29 de dezembro de 2020, de http://www.planalto.gov.br/

Brasil. Instituito Brasileiro de Geografia e Estatística - IBGE. Governo do Estado do Amapá. Secretaria de Estado do Planejamento. (2018b). Contas Regionais Amapá - PIB 2018. Recuperado em 20 de dezembro de 2020, de https://editor.amapa.gov.br/arquivos_portais/ publicacoes/SEPLAN_bcf47443edf2cac8a598983b9c218ad2.pdf

Brasil. Ministério do Meio Ambiente. (2018c). Procedimentos de Licenciamento Ambiental no Brasil - Amapá. Recuperado em 17 de dezembro de 2020, de http://pnla.mma.gov.br/

Brasil. Ministério Público Federal. (2019e). PORTARIA PGR/MPF nº 757, de 21 de agosto de 2019. Constituir, pelo prazo de 1 (um) ano, a Força-Tarefa "Estado do Amapá", destinada a investigar possíveis esquemas de corrupção no Estado do Amapá. Recuperado em 18 de dezembro de 2020, de http://mpr.mp.br

Brasil. Supremo Tribunal Federal - STF. (2016b). STF recebe ação contra lei do Amapá que cria licença ambiental única. Recuperado em 29 de dezembro de 2020, de http://portal.stf.jus.br/

Brasil. Supremo Tribunal Federal. (2020d, abril 20) Ação Direta de Inconstitucionalidade - ADI 5.475 Amapá. Recuperado em 18 de dezembro de 2020, de http://redir.stf.jus.br/

Brito, B. (2020). Nota Técnica sobre o Projeto de Lei 2.633/2020. Belém: IMAZON. Recuperado em 3 de março de 2020, de https://imazon.org.br/publicacoes/nota-tecnica-pl-2633-2020/

Chelala, C., \& Chelala, C. (2018a). O arcabouço institucional frente às transformações recentes na agricultura no Estado do Amapá. In: 560 Congresso da Sociedade Brasileira de Economia, Administração e Sociologia Rural - SOBER. Campinas: UNICAMP.

Chelala, C., \& Chelala, C. (2018b). O processo recente de expansão da soja no Estado do AmapáQuestões Institucionais. Recuperado em 15 de dezembro de 2020, de https://maissoja.com. br/o-processo-recente-de-expansao-da-soja-no-estado-do-amapa-questoes-institucionais/

Chelala, C., \& Chelala, C. (2019a). Soja no Amapá: história, economia e meio ambiente. Macapá: Clube dos Autores.

Chelala, C., \& Chelala, C. (2019b). O Arco Norte e a inserção do Amapá na rede de logística nacional. In Anais do 570 Congresso da SOBER. Recuperado em 29 de dezembro de 2020, de https://sober.org.br/wp-content/uploads/2020/05/9505.pdf.

Constituição Brasileira. (1988). Constituição da República Federativa do Brasil De 1988. Constituição, Brasília.

Constituição Estadual do Amapá. (1991). Constituição do Estado do Amapá de 1991. Estado do Amapá Assembleia Legislativa, Macapá. 
Evans, P. (2003). Além da "Monocultura Institucional": instituições, capacidades e o desenvolvimento deliberativo. Sociologias, 5(9), 22-63.

Gala, P. (2003). A Teoria Institucional de Douglass North. Revista de Economia Política, 23(2), 276-292.

Amapá. Empresa Brasileira de Pesquisa Agropecuária - EMBRAPA. (2016). Zoneamento socioambiental do Cerrado do Estado do Amapá. Relatório técnico sintetizado destinado ao conhecimento geral do estudo. Macapá: IEPA.

Homma, A. K. O., Menezes, A. J. E. A., Santana, C. A. M., \& Navarro, Z. (2020). O desenvolvimento mais sustentável da região Amazônia: entre (muitas) controvérsias e o caminho possível. Revista do Desenvolvimento Regional, 17(4), 1-27.

Instituto Brasileiro de Geografia e Estatística - IBGE. (2020). Cidades e estados. IBGE. Recuperado em 26 de dezembro de 2020, de https//www.ibge.gov.br/cidades-e-estados.

Instituto Nacional de Pesquisas Espaciais - INPE. (2020). Taxa de desmatamento-Amazônia Legal Estados - Amapá. Recuperado em 23 de dezembro de 2020, de http://terrabrasilis.dpi.inpe.br/.

Jorge, S. P. S. (2003). Política fundiária como instrumento de ordenamento territorial. (Dissertação de mestrado). Universidade de Brasília, Brasília.

Monteiro, T. (2020). A inconstitucionalidade do Licenciamento Ambiental Único previsto pela Lei Estadual do Amapa. Direito Ambiental. Recuperado em 29 de dezembro de 2020, de https://direitoambiental.com/a-inconstitucionalidade-do-licenciamento-ambiental-unicoprevisto-pela-lei-estadual-do-amapa/

Navarro, Z. (2001). Desenvolvimento rural no Brasil: os limites do passado e os caminhos do futuro. Estudos Avançados. 15(43), 83-100.

North, D. C. (2018). Instituições, mudança institucional e desempenho econômico. São Paulo: Três Estrelas. 